\title{
Humour With A Purpose: Creativity With Language In Facebook Status Updates*
}

\author{
Jenny Lewin-Jones (Worcester)
}

\begin{abstract}
This paper examines everyday linguistic creativity and humour in Facebook status updates. Analysis of the updates, collected in 2011 from 60 UK users, shows how people achieve particular humorous tones through creative combinations of lexis and syntax, adding reinforcements such as innovative punctuation to tighten the construction of the update. The linguistic features they use are not in themselves novel, but the creativity lies in the individuals' effective selection and use of them. The language is often playful, but the whole performance has a serious purpose: people invite a sympathetic perspective on themselves. Humour, particularly self-deprecation, is used to construct a personal narrative and thus perform their identity. In short, the paper celebrates the capacity of ordinary people to seize opportunities for using language skilfully and creatively to represent themselves and their lives.
\end{abstract}

\section{$1 \quad$ Introduction}

This paper explores linguistic creativity on Facebook, a social networking site which has become one of the world's principal locations for online discourse by ordinary people in everyday situations. The data analysed are status updates, hereafter referred to as "updates", from 60 UK Facebook users.

Updates are messages or comments which users share online with others. The posters often set these to be viewable only by their "friends", though they can set them to be seen by any Facebook user; they are in effect "publically personal messages" (Carr/Schrock/Dauterman 2012: 180).

Creativity matters on such platforms because it potentially gives people more control over the effectiveness of their messages, and thus of the communication process. Facebook is worthy of investigation because people use it in interesting ways, manipulating language to create their own personal style and often using humour.

The paper investigates how creative people are in this medium, whether there is a serious purpose to their playful language, and what this means for the capacity of ordinary people to use

\footnotetext{
* I would like to acknowledge the contribution made by Dr. Barbara Mitra in the first stage of the primary research.
} 
new opportunities to express views on things that matter to them. Thus it may offer general insights into digital communication (also referred to elsewhere as electronic or computermediated communication), the history of which "has been one of rapidly escalating creativity" (Goddard 2011: 141).

\section{Literature review on creativity, identity and humour in social media}

\subsection{Language creativity}

Creativity, or "the ability to act or think innovatively" (Giddens 1991: 41), is important if people are to make the world their own. Linguistic creativity is an "all-pervasive feature of everyday language" (Carter 2004: 13) including what Jean Burgess (2006: 5) calls "vernacular creativity". It is not just an individual achievement by exceptional people with particular creative qualities, but an effect of social conditions (cf. Fairclough 1995: 61); thus it may also be generated collectively as people communicate with each other.

Pinning down what is creative in the context of digital communication is difficult. Pre Facebook, some researchers sought to identify creativity in the features of what was sometimes seen as a new language, or "text speak". In early research into text messaging, three key sociolinguistic maxims were identified: "brevity and speed", "paralinguistic restitution" and "phonological approximation" (Thurlow/Brown 2003). David Crystal (2008) summarises features that give the impression of a distinctive language of texting: pictograms and logograms, initialisms, omitted letters, nonstandard spellings, and shortenings. Caroline Tagg (2012) prefers the term "respelling" rather than "non-standard" spelling, highlighting the deliberate decisions made by the users. Beverly Plester, Clare Wood and Puja Joshi (2009: 156) describe children's text messaging style as "creative expressions of children's engagement with language".

However, claims in the media (see Thurlow 2006) about the linguistic novelty and impact of text messaging were counteracted by studies of text messaging that found a low frequency of acronyms and emoticons (e. g. Ling/Baron 2007). Others argued that these features are not novel (cf. Shortis 2007; Crystal 2008), and Christa Dürscheid and Carmen Frehner (2013), for example, questioned the claim of linguistic novelty that terms such as "Netspeak" imply.

Linguistic creativity might include rule-breaking, but the question arises about what the rules are. Each new technological development poses language challenges to users, who must work out in what ways they wish to use it or what affordances they perceive and take up (cf. Barton/Lee 2013). Conventions may be established through user-generated coping strategies or externally through prescriptive guides (cf. Baron 2002). Sharon Millar's examination of email netiquette guides found that style guides reinforce "linguistic correctness" (2009: 305), emphasising the norms of formal written language. However, Facebook guides on netiquette include little about how to use it linguistically. Several (Reeves 2007; Awl 2009; Burrows 2011) do not even mention style. Thus where Facebook creativity does involve rule-breaking, the rules are not specific to Facebook.

If creativity does not lie in linguistic invention, it may lie in "novel and unexpected uses of language" (North 2007: 540, my emphasis) and for Rodney Jones (2012: 6), this is "breaking out of old patterns and coming up with new ones". One aspect of creativity identified by cog- 
nitive scientists is combination (e. g. Boden 2003: 3). This has also been applied to the study of language, as people can "create affective impact through [...] recombination" (Burgess 2006: 6), a process which seems particularly important.

Creativity in language is interwoven with purpose. Being creative is a matter not just of product but also of process, of people as well as texts (Jones 2012). As Crispin Thurlow (2012: 179) says, "Creative practice is motivated by... the pragmatic, relational needs of participants as much as it is by their deliberate attempts to play with the norms of spelling, punctuation and grammar". In short, studying linguistic creativity raises issues about the purposes to which people put any new medium and their ingenuity in doing so.

\subsection{Creativity and the performance of identity}

The nature of digital communication creativity becomes clearer by noting a strong bond between creativity and the nurturing of interpersonal relations (cf. Carter/McCarthy 2004). Crispin Thurlow (2012: 186) too thinks that the "creativities of new media" are "intensely social".

A feature of Facebook's interpersonal communication is the presentation of identity, with identity meaning "who people are to each other" (Benwell/Stokoe 2006: 6). Most literature on identity suggests that identity can be constructed and worked on: the Facebook user is "in the centre of the world" (Dalsgaard 2008: 9), with people using it to pursue "self-presentational and social goals" (Thimm 2008: 343) and positioning themselves "as a certain kind of person" (Deumart 2013: 42). Creativity with language is part of this: for example, "Spelling is now a more flexible friend used for [...] identity performance" (Shortis 2007: 21).

Linguistic creativity has been seen as performance or presentation to an audience, as though the language users are actors on a stage, reflecting Erving Goffman's (1969) metaphors. Another theoretical angle is narrativity, where Anthony Giddens' concepts of reflexivity and narratives of self-identity are useful: "We are, not what we are, but what we make of ourselves" (Giddens 1991: 75). He also points out that the autobiographical narrative has to be worked at, re-ordered and sustained (cf. ibd.: 186).

From this narrativity perspective, Ruth Page (2010: 440) suggests Facebook updates are "... like a personalized chronicle, where the events are unified by their concentrated focus on the life experiences of the individual writer". Studies also identify the creation of contemporaneous, edited autobiographies. Rodney H. Jones (2012: 244) sees such discourses as "tools we use in the real creative act ... of creating ourselves".

There is a deliberateness about how individuals manage their identity online and how they want to be seen, with language "a crucial form of cultural capital in asserting identities" (Barton/Lee 2013: 68). Naomi S. Baron's chapter on Facebook is "My best day" - a reference to how one user said that she wished to present herself on Facebook (cf. Baron 2008: 71). Facebook enables people to represent their lives by drawing on a "range of creative communicative practices" (Lee 2011: 124).

Performing identity and telling stories about oneself involves taking a stance, in other words evaluation and self-positioning (cf. Jaffe 2009: 3). Although writing may explicitly spell out this stance, it often does it by its tone. Tone refers to "the manner or spirit in which discursive acts are performed" (Herring 2007) and may, for example, be serious/playful, formal/casual, 
contentious/friendly, cooperative/sarcastic. This use of "tone" in Susan C. Herring's classification of features of computer-mediated discourse draws on Dell Hymes' (1974) category "Key". This is the "K" in the mnemonic "SPEAKING" in his ethnography of communication model. Hymes (1994: 19) reinforces the importance of key as it can override the "overt content of an act", for example when an utterance is sarcastic. Hymes (ibd.) also points out that key may be indicated in nonverbal ways (e. g. a wink or gesture) or through stylistic features such as vowel length. In this paper, Herring's term "tone" is used rather than Hymes' "key", although the sense is the same.

However, to convey stance people develop not only tone, but more than that, an individual style (although the distinction between tone and style is sometimes blurred). As Scott F. Kiesling (2009: 191) says, "... a personal style is created through habitual stancetakings". Style is developed to perform for others, and Janet Maybin and Joan Swan (2007: 514) suggest creative language is "a reflexive practice in which speakers/writers assume responsibility for presentation to an audience". Confirming the importance of the audience, Caroline Tagg (2012: 3) says text messagers have a high awareness of the recipient and how they want to appear to them; they adapt their style and make different linguistic choices according to the recipient of the message (cf. ibd.: 178).

Such studies imply controlled performance, but sometimes a feature of creativity is spontaneity or experimentation. Janet Maybin and Joan Swan (2007: 511) say such creative language in everyday talk is "unplanned and unrehearsed, constructed on the hoof". Similarly, Bethan Benwell and Elizabeth Stokoe (2006: 278) suggest that identity work performed online is characterised by "experimental, resourceful creativity with language".

Spontaneity or a lack of rehearsal suggests play. Of course, not all play is spontaneous, for play has a number of different meanings e. g. 'to take part in sport' or 'to perform on a musical instrument'. However, a particular type of play, playfulness, is spontaneous and light-hearted. "Playful" is used by Susan C. Herring (2007) as one dimension of the scale of tones of digital communication. Brenda Danet (2001: 368) examined "playful, artful activity on the internet" in areas such as email and Internet Relay Chat. She analysed "ways that people have frolicked and gambolled and capered about with, or experimented with, the stuff of speech and writing..." (ibd.: 10), concluding that playfulness was flourishing online. Sarah North (2007: 553) points to a sense of choreography, and of creative conversational humour in an online chatroom being spontaneous and yet cohesive. Anne Lazaraton (2014) finds extensive language play in a political blog.

David Crystal (1998: 10) says language play, or ludic language, is deliberate manipulation of language rules for fun. The question is whether this play involves fun for its own sake or for a purpose. Language play is not only fun; it has inter-personal functions, helps people adapt, and fosters innovative thinking (cf. Cook 2000: 91). The humour behind playfulness is therefore well worth investigating to see what we can learn from it about people's communicative capacities, in particular whether creative, playful language involves attempts to highlight the humour in the situations being referred to. 


\subsection{Humour}

Crispin Thurlow (2012: 170) suggests "creative practice is more often than not shot through with humour". Many people use social networking sites as a "source of entertainment" (Ofcom 2013: 28), but there is more to humour than that. Research has shown that humour in digital communication establishes group solidarity and individuality (cf. Baym 1995), and, in text messaging, friendship maintenance "in which an almost steady flow of banter is used to maintain an atmosphere of intimacy and perpetual social contact" (Thurlow/Brown 2003).

Similarly, Carr, Schrock and Dauterman (2012: 185) found humour in approximately $20 \%$ of Facebook updates, confirming Facebook's role in "supporting interpersonal interaction". Natalie Pennington and Jeffrey A. Hall (2014: 17) identified a correlation between Facebook updates containing humour and the number of "likes" which those updates received from the users' friends, evidence that humour can help maintain a social network. Language which functions in this way to create social bonds could be described as "phatic" (cf. Finch 2013: 113-114).

Self-deprecating (self-denigrating) humour is noteworthy; Diana Boxer and Florencia CortésConde (1997: 282) say this is "... play-activity that makes the speaker the center of the verbal playing". Their discussion of self-denigration emphasises humour as performance: "By complaining about one's own physical, emotional or intellectual shortcomings, speakers show themselves self-effacing, allowing the addressee to perceive them as approachable" (ibd.: 281).

Alexandra Georgakopoulou's (2011) study explores self-deprecating humour in emails, and says it contributes to senders' "positive self-presentation" and may be face-saving. Laura West and Anna M. Trester's (2013) ethnographic study of Facebook points to a range of strategies used to navigate potentially face-threatening acts. They note the presence of playfulness and humour, with some responses "padded with laughter" (ibd.: 144).

There are various ways in which a humorous tone can be achieved. One is through incongruity, "an unexpected switch from one frame to another" (Georgakopoulou 2011), which may involve register clash (cf. Dynel 2009: 1291).

Another humorous tone is irony, which Ronald Carter and Michael McCarthy (2004: 75) identify as a creative use of language. Irony is based on discrepancy between known facts and attitudes and the words representing them. For irony to work, the recipient must understand the duality and decode the "real meaning", since ironic utterances deliberately misrepresent and are not meant to be taken at face value. Richard J. Alexander (1997: 127) considers irony in British humour as escapism from "regimented social forces", showing how speakers are enabled to "to say A and mean B".

In spoken communication "irony may be additionally coded by a tone of voice, a special intonation, tempo, and timbre" (Nash 1985: 153). The issue for the Facebook user is how to convey ironic and humorous tones using resources of written language alone, which some researchers see as "paralinguistic restitution" (Thurlow/Brown 2003), substitution for the bodily communication that is integral to face-to-face communication. 
In digital communication, the physical response to humour lies behind acronyms such as LOL ('laughing out loud'), perhaps compensating for the "absence of embodied action" (Benwell/Stokoe 2006: 264). Tone and humour are also indicated by other markers ("reinforcements" as they are called in this paper). Emoticons are well known, but punctuation is also used, flexibly and creatively. Ellipses in text messages may mean omissions, (dramatic) pauses, full stops, question marks, or added emotion (cf. Baron/Ling 2011: 60-61). Multiple exclamation marks and reduplication of final-word vowels could be "markers of enthusiasm and intensity" (Tannen 2013: 104).

Audiences' interpretations of such resources matter. Emoticons closely depicting the expression they represent are widely understood, e. g. a face with downturned mouth for sadness (cf. McDougald/Carpenter/Mayhorn 2011: 1949). A message with a smiley emoticon is rated more positively than one without (cf. Derks/Bos/Von Grumbkow 2008: 385). Email recipients draw inferences about senders' emotional states from punctuation, with multiple exclamation marks here said to indicate happiness (cf. ibd.: 406). However, infrequently used stance markers may be less understood, so writers' intentions and receivers' interpretations can differ.

The thrust of this literature review is that it is of interest to examine the language in Facebook posts, but essential to consider this in the context of what they are used for. Humour in particular pinpoints some of the purposes of updates, and ways people use language for particular effect, especially their stance on topics being discussed.

Thus further investigation is warranted, and this paper tries to unpick some of the intertwined threads of identity construction, humour and linguistic creativity.

\section{$3 \quad$ Methodology}

Researchers have difficulty in accessing digital communication (cf. Crystal 2011: 13), and studying Facebook is tricky, with much of it closed to outside observers. Few users leave their updates public; most narrow the privacy setting so they are viewable only by "friends". Ethical concerns must be addressed (cf. Zimmer 2010: 314), and studies show concerns by Facebook users about privacy management on it (cf. Boyd/Hargittai 2010; Bornoe/Barkhuus 2011).

A colleague and I collaborated to capture real-life posts by ordinary users, then used the database separately. We jointly collected samples of updates, wanting data which was representative of everyday Facebook usage (cf. Tagg's 2012 study of text messaging). Our study focuses on updates, not the responses to them; Ruth Page (2010) uses a similar approach.

This evidence therefore forms a case study. It consists of individuals' use of Facebook during January-July 2011, a key period as Facebook had expanded to a wide section of the UK population, but users were not yet frequently re-posting messages from organisations or uploading multi-media content. It thus meets Crispin Thurlow's (2013: 243) call for research upholding "truly social - often banal, always embedded - practices of ordinary communicators" rather than what he calls "Fakebook", the pseudosocial uses of social media by commercial corporations, politicians and educational institutions etc. for professional or commercial goals. 
Our data collection also predates the rise of the selfie, the sharing of self-portraits online. Caroline Tagg (2015: 66) says of the selfie: "Never has it been easier for so many people to play with their identity and to do so in front of so large an audience". Our data therefore usefully forms a snapshot of a period when Facebook users were building a self-image predominantly through words and linguistic creativity.

We sought users whose identity could be verified, but deleted identifying details (the names shown are pseudonyms). Some users were already our own Facebook friends, and through a snowballing process they asked others if they would participate. This recruitment process is similar to that of Caroline Tagg's (2012) study of text messages. As with many other studies of digital communication (cf. Lazaraton 2014), this paper does not include user demographic data except gender and age. The 60 individuals in the study were divided equally between males and females, and the ages ranged from 11 years old to over 60 . It proved hardest to recruit under $18 \mathrm{~s}$, as some parents were reluctant to give consent, so there were only 6 in total under 18, although there were 15 under twenty and so for the purposes of analysis, our lowest age group was therefore taken as $<20$.

We cannot know for certain whether all information disclosed about gender and age is true, but it is reasonable to assume that it is; however we do not know the users' ethnicity or socioeconomic background. We do not claim that it is a cross-section of UK Facebook users, but there are indications that it includes a sufficiently broad range to allow us to identify the wide variety of current linguistic practices and strategies, which is the main aim of this paper.

To gather the data from updates we, the researchers, had to be accepted as a Friend so participants did not have to alter their privacy settings. At the close of data collection, we were "defriended", as advocated by Alexandra D'Arcy and Taylor M. Young's (2012) model for ethical research on Facebook. Consent forms were sent to the participants, preceded for the under $18 \mathrm{~s}$ by parental consent forms. Updates were collected from $1^{\text {st }}$ January 2011 , six months prior to the start of the data gathering, thus users' writing styles were not influenced by awareness of the study.

We collected the first 20 updates posted by each individual from the starting date, so with 60 individuals included, we had 1,200 updates in total. The sample size of 20 was chosen to enable us to see each user's style and usage pattern. This is important. John Gumperz (2000: 131) says that listeners' inference in verbal encounters relies on "preceding talk, their expectations about what is to follow, as well as on culturally specific background acquired through previous communicative experience". This almost certainly also applies to Facebook status updates, thus requiring us to interpret individual updates in the context of those preceding and following them.

Update topics were classified using Susan C. Herring's (2007) categorisation, divided into our own subcategories: Self (personal information and observations), People (comments on people known personally e. g. family, friends), Artefact or Event (comments on films, exhibitions, football matches, cars, etc.), Transaction (e. g. friendship maintenance comments such as thanks for birthday wishes, or party invitations), External Issues (e. g. comments on weather, politics, deaths of famous people). 
The tone of each update was then examined to see which were humorous, corresponding to the "playfulness" element of Susan C. Herring's tone category. This codification of humour followed the procedure taken by Carr/Schrock/Dauterman (2012: 185), in which coders noted humour if they "perceived the speech act was an attempt to be witty, funny, ironic, or mirthful". The updates classified as humorous were subsequently analysed further, using subcategories of conversational humour identified by Marta Dynel (2009: 1284), notably selfdenigrating humour (termed self-deprecation in this paper), allusion, hyperbole, irony, anecdotes, humorous lexemes, and register clash.

To increase reliability, two researchers coded all the updates (cf. Carr/Schrock/Dauterman 2012). There is inevitably an element of subjectivity in the codification, but the methodology does enable the identification of the range of practices, and the significant features that dominate.

The findings section begins by analysing the topics of users' updates, and then how some achieve a humorous tone through the creative use of lexis, syntax, and reinforcements.

\section{$4 \quad$ Findings}

\subsection{The dominance of the topic of self and the centrality of humour}

The first striking feature of the updates is that many are about Self, thus emphasising Facebook's self-presentational role. All users except one have updates coded as Self, and $61 \%$ of all updates are about Self, though this varies slightly by gender ( $66 \%$ for women, $57 \%$ for men).

Some updates coded as Artefact, Transaction or External are also about Self too, so the theme of self dominates. Most updates about friends or family also refer to Self. For example, the following three users each refer to their parental role:

Has been deserted by Karen so she can go boozing in Birmingham leaving me to construct the most complicated children's garden slide in the world (Sebastian, 30-39)

Now knows that taking two kids under ten to a music festival isn't that good an idea (Percy, 40 49)

How difficult is it to get a 6 year old to do his thank you letters, grrrrrrrr (Harriet, 30-39)

By contrast, fewer updates (7\%) are solely about other People, though users who post these tend to do so regularly. For instance, one frequently writes about her daughter:

Poor Anna has infected thumb nail after bizarre Xmas cracker toy accident last week (don't ask!) so now has a 'Tom and Jerry' style big bandage on her thumb! (Eliza, 40-49)

Most users who have few Self updates have a high number of External updates, and are largely single-issue posters. For example, Mark posts extracts from his environmental issues blog, and Melvin summarises news from a trade union.

Users' stances on topics are signalled by the tones they adopt. How users indicate tone, and how it was identified, is analysed below (4.2-4.4), but first, some general observations on users' humour when writing about Self may be useful. Humour is found in $22 \%$ of updates, and most users have at least one humorous update. There is a strong connection between the 
topic of Self and humour: of the updates about Self, 31\% include humour, whereas of the other topics taken together, only $15 \%$ do.

Humour about Self is more likely than other humorous topics to have an identifiable evaluative stance (favourable or unfavourable), with self-deprecating humour common:

Got my first ever new iron - how sad that I wanted to try it out! Better not make a habit of it. (Elizabeth, 40-49)

Some of people's self-deprecation actually refers to their use of Facebook:

Crumbs steep learning curve! Thanks for the various welcomes. Good to be here, although inbox in overdrive and space bar not working. How do I fit in a life around Facebook? (Sally, 3039)

Although Facebook has no restriction on update length, most updates in this study are two or three lines long, with the average 12.9 words. There were exceptions: some contained no words, consisting of a link to a website or photo, and a few users wrote lengthy updates (the longest were from Mike, age over 60, with an average word count of 37.5 words), though these tended to be non-humorous updates about External issues. There was some age difference: for people under 40 the average was 10.2 words per update, whereas for the over $40 \mathrm{~s}$ this was 15.8, but this difference is largely accounted for by those older users with long updates. Moreover, there was no significant difference in word count between the genders. The key finding is the brevity of most updates, and the paper now examines how the users writing about Self managed to show creativity and humour within so few words.

\subsection{The humorous images of self}

The self-deprecating humour is achieved in a number of ways. One of these is through allusion, reference to something already familiar to the reader, a contextualisation cue of culturally shared knowledge (cf. Gumperz 2000, 2006). For example, in the following update, the humour comes from the reader's knowledge of the television advertisements for the 118-118 telephone directory service:

Needs to ditch his new running shorts that make him look like a reject from the 118-118 ads (Sebastian, 30-39)

Another way of creating a self-deprecating tone is hyperbole, or exaggeration. This trope often involves the poster conjuring up a ludicrous visual image for the reader, as in Alfie's update about his over-spending and Vicky's about her giant-sized cat:

If I cant stop internet shopping soon, might actually have to eat my debit card to stop myself. (Alfie, aged 18-20)

It's difficult trying to get into bed when a cat that doesn't want to move is taking up $3 / 4$ of a kingsize bed!! (Vicky, 50-59)

Sometimes the humour needs more unpacking. In the next example, the reader has to "get" the incongruity of Mickey Mouse, a loveable character, officiously searching customer's bags for contraband. The reader also has to understand the criticism of the cost of refreshments at Disneyland, and Percy's exaggeration of the amount saved by taking their own water. The humour here lies in the blend of hyperbole, allusion and incongruity, all rolled together into a 24-word update: 
Eurodisney here we come. Apparently Mickey doesn't frisk your bags for bottled water on the way in, so that'll save a few hundred quid. (Percy, 40-49)

Self-deprecating tones may also be generated by irony. For example:

Plant mister bought. Plants well misted. Yes, my life is exciting. (Mason, 20-29)

In that example, Mason uses irony to imply the opposite of what his final statement says, and the irony is contained in the words alone. Irony strictly defined, is quite rare, $3 \%$ of updates, but more use an ironic tone e. g. understatement:

a hungover train journey isn't really what I need (Nita, 20-29)

In that update, Nita could have used hyperbole or exaggeration to show how much she was suffering from her hangover. Instead, she uses the opposite, litotes, understating how she feels about the train journey. Both tropes present the user's "plight" humorously to elicit sympathy and show they can laugh at themselves.

Self-deprecating updates can also use anecdote to convey the humour. Some of these updates may be longer than average, to build up a story, for example:

My arm aches after having to have a tetanus injection due to my overzealousness playing football with my son. I wanted to win (and prove that women can play football) and ended up in bed of roses and gashing my arm with thorns. Ouch. I was all for carrying on but my more sensible son told me to get a plaster and stop playing! (Brenda, 40-49)

In that anecdote, the actual incident of scratching her arm badly was not in itself humorous, but Brenda's retelling turns it into comedy. She leads up to the humour of her son being the "adult" who recommends the first aid; this could be considered a "punchline", a term taken here to include any tag or pay-off line serving as an update's climax, particularly a humorous one. These self-deprecating updates fit into a "laugh about it later" category of social humour in which "Laughter is the mode of telling the story, not part of its content" (Billig 2005: 233).

In addition to these rhetorical devices, humorous tone is also conveyed by lexis, since choice of words can indicate the user's own stance towards the topic. Words such as great, super, chuffed, outstanding, winner, amazing show a positive stance on the topic. By contrast, words like bored, sulky, sad, shit, bad, downer, gutted indicate a negative stance. To borrow a term from Caroline Tagg's (2012) study of texting, these are "lexical stance markers" (ibd.: 119).

Beyond indicating stance, words and phrases may be chosen because they have particular resonance and are in themselves humorous lexemes e.g. bliss, blooming well, buzzin for, cheers loads, crumbs, bugger, pile of crap, chuffing ("chuffing blokes"), if only.., screw you. They may use a particular register e. g. babytalk (hurty), or contribute to an overall conversational style, characterised by informality and intimacy.

Users are also willing to play around with lexis. Here, in the "punchline" Hazel tries out synonyms for nothing in different registers:

Blimey my banishment from the net didn't last long, just rang 3 and the cable I found in my mobile phone box tonight (only languished in there for 18 months unused) connects me to the net via my phone, and no charge - nada, nil, nuffink!! :O (Hazel, 50-59)

In that update, Hazel creatively uses the repetition and juxtaposition of humorous lexemes to complement the anecdotal style. What could have been an inconsequential occurrence (finding a cable for her phone) turns into an amusing tale. 


\subsection{Other resources to reinforce the humorous tone}

Lexis and stylistic devices such as hyperbole are frequently supplemented by other resources (or markers), showing how the update is to be interpreted. These reinforce the tone of the update, and so in this paper are called "reinforcements". They highlight the update's emotion and its intensity.

The most immediately striking of the reinforcements are the emoticons, for example :). Individuals sometimes have a "signature emoticon", using it frequently. For example, Alfie (1820 ) has :D or $x D$ at the end of eleven of his 20 updates, where other users might have exclamation marks:

Merry Christmas everyone :D (Alfie, 18-20)

Playfulness with such devices occurs among all age groups. For example, Frances (age 13) uses a range of emoticons, hearts and kisses, conveying emotion with the briefest of postings:

Birthdayy todayy :D $\bullet$ (Frances, 13)

Stance and tone are also contributed by speech-like discourse markers. These are sometimes onomatopoeic and often elongated, a form of paralinguistic restitution. Examples include: achooooooooo, boo hoo, boo-ya, blahhhhh, blerghh, erm, errm, grrr, heehee, hmmm, hurrah, ooooo, oops, wahay, wooo, woohoo, woop woop, woops, wow, yayy, yey, yippee, yuuиus, and lexemes that are respelled and used as a discourse maker such as supah. The initialism lol could also be placed in this category.

Playful respellings may also achieve phonological approximation (cf. Thurlow/Brown 2003). For example, Cindy uses em and lil. The way she constructs her update emphasises her humorous perspective on her morning spent looking after young children:

Ok so far so good with the kids. Made em breakfast, played with Mr Potatohead and a garage, lil mishap with the squash which means we now have a hyper 3 yr old, must be mid day by now... ohh no the sun is only just coming up! Long day ahead methinks lol (Cindy 20-29)

Another user reinforces his humorous tone with the regiolectal respelling sumat for 'something', and the phonetic spelling rite for 'right', alongside playfulness with language features such as logograms and initialisms. These features in isolation are not new or creative, but the way they are juxtaposed is, which adds to the humorous tone. For example, the following analogy between an ineffective internet connection and a student suffering after New Year's Eve drinking is witty, and Aidan's friends will see a reference to his own hangovers but it is the respellings that draw attention to the colloquial style:

My internet is bein a rite dickhead 2day maybe its hungover from nye or sumat (Aidan, 20-29)

Different reinforcements can be used for the same effect. For example, the emphasis generated by the above resources can alternatively come from elongation e. g. soooo, or capitalisation e. g.:

Assignments FINITO! (Eve, 20-29)

Alternatively, several punctuation features may be used in combination, magnifying their effect, e. g.: 
Wooo HOLIDAY diet starts tmw with the gym I'm a member of and haven't been 4 months OOPs! Heehee! (Candace, 20-29)

In that update, Candace's self-deprecating tone, scolding herself for not having been to the gym, is made humorous by the excited Wooo, capitalisation of HOLIDAY, the mock guilty OOPs! and the final laughter indicator Heehee!.

Punctuation (here, exclamation marks) may reinforce capitalisation or lexis that already carries strong emotional force:

FUCK OFF ASSIGNMENT!!!!!!!!!!!!!! (Danny, 20-29)

None of these resources are used exclusively for humour, but they do direct the reader to realise that some tone and emotion is intended.

However, the user's regular style matters. If users rarely use exclamation marks, then they can indicate an intense emotion just with a single one. In contrast, if they habitually use multiple exclamation marks, then intensity of emotion may need this ratcheted up. One such user is Joe, who regularly uses multiple exclamation marks and creative emoticons, e. g.

Tricky, Martina Topley-Bird, Public Enemy winner !!! One of my favourite records :0)))))) (Joe, 40-49)

Equally, when people such as Joe frequently use markers, their absence in an update is meaningful and can show intensity of feeling, e. g.:

$50 \%$ of Tory funds come from City $£ 11.4 \mathrm{~m}$. Barclays Plc Chief Executive Officer maybe getting $£ 8$ million bonus. Most of Birmingham Citizens Advice bureau Offices maybe closing due to cuts. (Joe, 40-49)

Another reason for the absence of any reinforcements can be in the case of dry humour, which works because readers are left to identify the humour for themselves:

So, when they say "adapted from a story by M R James", they mean "we nicked the title and attached it to our own rubbish story." (Jane, 50-59)

After an 8 hour shift, my feet are officially bloody stumps. They have 6 hours to recover before I give them another 8 hour pounding and turn them into something that resembles corned beef. (Andrea, 40-49)

In such deadpan humour, adding anything further, such as a blatant $L O L$, to indicate that the tone is humorous would actually diminish it.

Thus there is not a sliding scale where the number of resources indicates the degree of humour. When identifying tone in an update, the range of markers and lexis routinely used by the individual should be taken into account, so a reader needs some familiarity with the user's habits in order to interpret it.

In analysing their use, some minor differences between age groups and genders can appear. For example, males under 20 used "text speak" more than any other group e. g. clipping final letters of words, shortening words, respelling, capitalisation for emphasis, using emoticons, elongating words, and repeating punctuation marks. However, there were few males under 20 in the study, so this finding is not highly significant: certain individuals used a particular feature repeatedly, and this influenced the average for the group. By contrast males over 40 used the least "text speak", although this may be due to the content of their updates, as they had the 
most categorised as External or Transactional, often written in more formal English, with conventional spelling and punctuation.

In short, a whole palette of devices is available: the mix varies from person to person, as people create their own style to convey their desired tones.

\subsection{Constructing the update and reinforcing the pattern}

However, the humorous tone is achieved not through adding the above features randomly, but by constructing the whole update as a careful sequence of stages, including reinforcements which bolster the syntax and make the construction more transparent. Doing this makes it possible to convey sometimes complex humorous messages even in brief updates.

A variety of update patterns are found. In the following update, the humour lies in the escalation of feelings during the update. Nathan shows this by starting with standard spelling and sentence structure, then using the informal respellings gonna and outa, and finally adding an expletive, more respellings and multiple exclamation marks, these features together constituting another example of paralinguistic restitution:

Uni are 'trying' to say that they have paid $£ 150$ quid into my account and are gonna take it outa my bursary in feb... good luck with that one fuckers!!! You aint goin anywhere near my account!!! (Nathan, 18-19)

Anecdotes are frequent in updates, and some of these use asides, which are commonly humorous lexemes or discourse markers, such as the ones in brackets here:

Hubby Sean now back from India with lots of Indian sweets (yum). And the cutest little silk Kurta pyjamas for Harry. A little too big for him yet, but in the summer it'll be perfect. Dry clean only though (eek). (Kristin, 30-39)

In that three-letter aside (eek), Kristin conveys rueful exasperation at her husband's failure to realise the impracticality of buying a child pyjamas which cannot be washed.

Some updates are constructed to parody familiar contexts. Joe, for example, uses a "question $\&$ answer" format, Hazel imitates football chants, and Vicky mimes pantomime repartee between actors and audience:

Q. Bit of a shit day? A. Well yes, as it happened, bit of a bollock buster ;o)

Q. What do you need? A. A master at the top of his game playing something written by a genius please :O) (Joe, 40-49)

Super, Super Leeds, Super, Super Leeds, Super, Super Leeds, SUPER LEEDS UNITED. (Hazel, 50-59)

Is looking forward to our family trip to the Panto this afternoon, Peter Pan. Oh yes she is! Lol. (Vicky, 50-59)

The first part of Vicky's update merely reports the fact of the family outing, but Vicky creatively turns this into humour update with the parodic Oh yes she is!. The Lol at the end of the update reinforces the humorous intention.

Many humorous updates juxtapose two elements. Elizabeth here uses contrasting emoticons to signal the change in mood within her anecdote. The first part ends with a classic smiley face emoticon, but the second ends with a colon and brackets indicating a very sad face, a considered, creative use of resources: 
Robbie learnt to ride his bike today! I've been out on my bike too. :) Then...... fell off the roundabout, banged my leg:(( That's a playground roundabout not one in the middle of the road btw. (Elizabeth, 40-49)

With many updates, the final part can be seen as a "punchline", here accentuated by exclamation marks:

Is it only me that when ur in the car wash there's always that little bit of temptation to open the window?? Heehee!! (Candace, 20-29)

Is rubbish at a game that 10 year olds can play, screw you Laserquest!! (Nerys, 20-29)

Ellipses can also be used or added to emphasise the contrast between the "punchline" and the rest of the update:

Cars just broken down in Ombersley....joy. (Allie, 18-20)

Bugger. 8 weeks of placement about to start and I've caught a cold from the snotty woman on the plane... achoooooooo! (Andrea, 40-49)

In Rachel's narrative, the whole story is given immediacy by omitting capitalisation, and the ellipses this time build up to the self-deprecating "punchline":

went to party last night, wasn't told it was 70 s theme.... popped home, 2 mins later was redressed in 70 s type garb.... returned and had great time... what does this say about my wardrobe??! (Rachel, 30-39)

Some reinforcement resources thus function like the "dramatic staging" in exchanges in an internet chatroom, where tension and immediacy are created through dramatic pause ellipses, reduplicated punctuation and capitalisation (cf. Thurlow 2012: 180). Similarly, emoticons are almost a hybrid of the end-of-sentence full stop in traditional writing and end-of-sentence laughter in face-to-face conversation.

There is no separation between the two "halves" in the following update, but a heart emoticon at the end augments the irony of the second statement:

Was back at uni today and my first lecture lasted 45 minutes. I can see they are really going to push me this semester $\vee$ (Laura, 20-29)

Friends might spot irony because they know the situation or person (Laura's friends would know that the standard lecture time is longer), but reinforcements help others identify the tone even when unaware of the underlying "truth condition" (Nash 1985: 153).

Tone can also be conveyed by adding other, arguably more novel and playful, reinforcements such as asterisks around words to highlight them, hashtags (in the style of Twitter), and ".com" (aping website names which summarise their content):

Writing about Shale tonight. Gosh *how* exciting. \#liar \#liar \#bum \#on \#fire (Cate, 30-39)

Gotta love being at hospital at half 12 at night. Shattered.com. (Deirdre, 20-29)

In both those updates the punctuation in the second half is used to point out the ironic tone of the first half. Cate indicates that working on her essay is far from "exciting", and Deirdre does not "love" being late at the hospital.

Thus a whole range of features comes together to compose a humorous update. Most users, whatever their age and gender, had their own idiosyncratic style. What stood out especially 
was their skill in blending together a range of features in order to produce individually created humorous tones.

\section{Conclusion}

The Facebook users in this study most frequently post about themselves and their own lives, prominently using humorous tones, and particularly self-deprecation. On the face of it, this merely shows their ability to laugh at life's absurdities, and not take themselves seriously. However, the purpose of this performance may be to invite solidarity and a sympathetic view of themselves and their lives, in ways their audience can identify with.

In constructing this identity narrative, users are impressively creative with the language tools at their disposal. The Facebook users in this study achieve humour through such means as allusion, hyperbole, irony, anecdotes, and humorous lexemes, reinforced by creative use of resources such as punctuation. The devices used may not in themselves be novel, creative or humorous, but the users achieve humorous tones through creative combination and juxtaposition of elements within what are mostly very brief updates.

The reinforcements such as emoticons and punctuation are interesting, but their main function is to reinforce the syntactical construction of the updates, which is arguably more creative than the reinforcements themselves. "Punchline" patterns in particular stand out as a way of indicating humour.

Users deploy lexis, constructions and other resources cleverly, subtly and maybe knowingly to convey nuanced tones (and thus particular evaluative stances) on what they are posting about. Each user conveys a particular perspective on themselves through their selection of language resources. However, as the literature suggests, the semi-public nature of Facebook and complex interactions between users may mean their creativity and humour also result from collective endeavour, not just individual acts.

Of course, the capacity of people to be linguistically creative is operating here in a relatively limited sphere (principally updates about the self), and there may be ideological constraints preventing people from extending that creativity. Gilles Deleuze's view (1992: 6) is that we have become "dividuals" in a society of control, and Tero Karppi (2011: 7) says the Facebook experience may seem personal but users are actually part of demographics or masses "whose desires and consumptions are manipulated and controlled". This is especially pertinent as targeted advertising on Facebook has grown since this study's data was gathered. However, it is frequently acknowledged that users do have some agency or control (cf. Baron 2008: 84), and the creativity shown by users in this study, however limited, is important - it demonstrates people's capacity to influence the world they are a part of, rather than be completely controlled by it.

What the paper foregrounds is people's ability to use language in creative and adaptive ways. Facebook will inevitably be supplanted by other communication and friend-work tools, but the creative and humour-full performance of identities is likely to continue in new contexts via users' ingenuity and language playfulness in all its forms. 


\section{References}

Alexander, Richard J. (1997): Aspects of verbal humour in English. Tübingen: Narr.

Awl, Dave (2009): Facebook me! Berkeley, California: Peachpit Press.

Baron, Naomi S. (2002): "Who sets email style? Prescriptivism, coping strategies, and democratizing communication access". The Information Society 18/5: 403-413.

Baron, Naomi S. (2008): Always on: Language in an online and mobile world. Oxford: Oxford University Press.

Baron, Naomi S./Ling, Rich (2011): "Necessary smileys and useless periods". Visible Language 45/(1/2): 45-67.

Barton, David/Lee, Carmen (2013): Language online. Investigating digital texts and practices. London: Routledge.

Baym, Nancy K. (1995): "The performance of humour in computer-mediated communication". Journal of Computer-mediated Communication 1/2. http://onlinelibrary.wiley.com/ enhanced/doi/10.1111/j.1083-6101.1995.tb00327.x [24.11.2014].

Benwell, Bethan/Stokoe, Elizabeth (2006): Discourse and Identity. Edinburgh: Edinburgh University Press.

Bergs, Alexander (2009): "Just the same old story?" In: Rowe, Charley/Wyss, Eva L. (eds.): Language and new media. Linguistic, cultural and technological evolutions. Cresskill, New Jersey, Hampton Press: 55-73.

Billig, Michael (2005): Laughter and ridicule. Towards a social critique of humour. London: Sage.

Boden, Margaret A. (2003): The creative mind: Myths and mechanisms. $2^{\text {nd }}$ ed. London: Routledge.

Bornoe, Nis/Barkhuus, Louise (2011): "Privacy management in a connected world: Students' perception of Facebook privacy settings". ACM conference on Computer Supported Cooperative Work, 19-23 March, Hangzhou, China. http://bornoe.org/papers [29.07.2015].

Boxer, Diana/Cortés-Conde, Florencia (1997): "From bonding to biting: Conversational joking and identity display". Journal of Pragmatics 27: 275-294.

Boyd, Danah/Hargittai, Eszter (2010): "Facebook privacy settings: Who cares?" First Monday 15/8. doi: 10.5210/fm.v15i8.3086.

Burgess, Jean (2006): "Hearing ordinary voices: Cultural studies, vernacular creativity and digital storytelling". Journal of Media and Cultural Studies 20/2: 201-214.

Burrows, Terry (2011): Blogs, wikis, Facebook and more. Everything you want to know about using today's internet but are afraid to ask. $2^{\text {nd }} \mathrm{ed}$. London: Carlton Books.

Carr, Caleb T./Schrock, David B./Dauterman, Patricia (2012): "Speech acts within Facebook status messages". Journal of Language and Psychology 31: 176-196.

Carter, Ronald (2004): Language and Creativity. The art of common talk. Oxford: Routledge.

Carter, Ronald/McCarthy, Michael (2004): "Talking, creating: Interactional language, creativity and context". Applied Linguistics 25/1: 62-88.

Cook, Guy (2000): Language Play, Language Learning. Oxford: Oxford University Press.

Crystal, David (1998): Language play. Chicago: University of Chicago Press.

Crystal, David (2008): Txtng. The Gr8 Db8. Oxford: Oxford University Press. Crystal, David (2011): Internet linguistics. London: Routledge. 
Dalsgaard, Steffen (2008): "Facework on Facebook. The presentation of self in virtual life and its role in the US elections". Anthropology Today 24/6: 8-12.

Danet, Brenda (2001): Cyberpl@y. Oxford: Berg.

D'Arcy, Alexandra/Young, Taylor M. (2012): "Ethics and social media: Implications for sociolinguistics in the networked public". Journal of Sociolinguistics 16: 532-546.

Deleuze, Gilles (1992): "Postscript on the societies of control". October 59: 3-7.

Derks, Daantje/ Bos, Arjan E. R./Von Grumbkow, Jasper (2008): "Emoticons and online message interpretation". Social Science Computer Review 26/3: 379-388.

Deumart, Ana (2013): "The performance of a ludic self on social network(ing) sites". In: Seargeant, Philip/Tagg, Caroline (eds.): The Language of Social Media: Identity and Community on the Internet. Basingstoke, Palgrave Macmillan: 23-45.

Dürscheid, Christa/Frehner, Carmen (2013): "Email communication". In: Herring, Susan C./Stein, Dieter/Virtanen, Tuija (eds.): Pragmatics of computer-mediated communication. Berlin/Boston, Mouton de Gruyter: 35-54.

Dynel, Marta (2009): "Beyond a joke: Types of conversational humour". Language and Linguistics Compass 3/5: 1284-1299.

Fairclough, Norman (1995): Media discourse. London: Arnold.

Finch, Geoffrey (2013): Word of mouth. $2^{\text {nd }}$ ed. London: Palgrave Macmillan.

Georgakopoulou, Alexandra (2011):" 'On for drinkies?': Email cues of participant alignment". Language@Internet 8/4.

www.languageatinternet.org/articles/2011/Georgakopoulou [12.05.2015].

Giddens, Anthony (1991): Modernity and self-identity. Cambridge: Polity Press.

Goddard, Angela (2011): "look im over here: Creativity, materiality and representation in new communication technologies". In: Swann, Joan/Pope, Rob/Carter, Ronald (eds.): Creativity in Language \& Literature. Basingstoke, Palgrave Macmillan: 141-155.

Goffman, Erving (1969): The presentation of self in everyday life. London: Penguin.

Gumperz, John J. (2000): "Inference". Journal of linguistic anthropology 9/1-2: 131-133.

Gumperz, John J. (2006): "Contextualisation conventions". In: Paulston, Christina B./Tucker, G. Richard (eds.): Sociolinguistics: the essential readings. Oxford, Blackwell: 139-155.

Herring, Susan C. (2007): "A faceted classification scheme for computer-mediated discourse". Language@Internet, 4/1.www.languageatinternet.org/articles/2007/761 [29.10.2012].

Hymes, Dell (1974): Foundations in sociolinguistics: An ethnographic approach. Philadelphia: University of Pennsylvania Press.

Hymes, Dell (1994): "Towards Ethnographies of Communication". In: Maybin, Janet (ed.): Language and Literacy in Social Practice. Clevedon, Multilingual Matters: 11-22.

Jaffe, Alexandra (2009): "Introduction. The sociolinguistics of stance". In: Jaffe, Alexandra (ed.): Stance: sociolinguistic perspectives. Oxford, Oxford University Press: 3- 28.

Jones, Rodney H. (2012): "Skating across timescales: creativity in dynamical systems". In: Jones, Rodney H. (ed.): Discourse and creativity. Harlow, Pearson Education: 232- 246.

Karppi, Tero (2011): "Digital suicide and the biopolitics of leaving Facebook". Transformations 20. www.transformationsjournal.org/journal/issue_20/article_02.shtml [26.06.2013].

Kiesling, Scott F. (2009): "Style as stance". In: Jaffe, Alexandra (ed.): Stance: sociolinguistic perspectives. Oxford, Oxford University Press: 171-194. 
Lazaraton, Anne (2014): " 'And, worst of all, habeus was corpsed': Language play using a passive voice frame on the Daily Kos weblog". Language@Internet 11/2. www.languageatinternet.org/articles/2014/lazaraton?searchterm=laza [13.08.2014].

Lee, Carman K. M. (2011): "Micro-blogging and status updates on Facebook: Texts and practices". In: Thurlow, Crispin/Mroczek, Kristine (eds.): Digital Discourse. Language in the New Media. Oxford, Oxford University Press: 110-128.

Ling, R./Baron, N. S. (2007). "Text messaging and IM: Linguistic comparison of American college data". Journal of Language and Social Psychology 26/3: 291-298.

McDougald, Brannan R./Carpenter, Eric D./Mayhorn, Christopher B. (2011): "Emoticons: What does this one mean?" Proceedings of the Human Factors and Ergonomics Society Annual General Meeting 55: 1948-1951.

Maybin, Janet/Swan, Joan (2007): "Everyday creativity in language: Textuality, contextuality and critique". Applied Linguistics 28/4: 497-517.

Millar, Sharon (2009): "Technologies and techniques. The (N)etiquette of telephone and email communication". In: Rowe, Charley/Wyss, Eva L. (eds.): Language and new media. Linguistic, cultural and technological evolutions. Cresskill, New Jersey, Hampton Press: 285-311.

Nash, Walter (1985): The language of humour. Harlow: Longman.

North, Sarah (2007): "'The Voices, the Voices': creativity in online conversation". Applied Linguistics 28/4: 538-555.

Ofcom (June 2013). Being online: an investigation of people's habits and attitudes. http://stakeholders.ofcom.org.uk/binaries/research/media-literacy/being-online.pdf [11.06.2013].

Page, Ruth (2010): "Re-examining narrativity: small stories in status update". Text \& Talk 30 14: 423-444.

Pennington, Natalie/Hall, Jeffrey A. (2014): "An analysis of humor orientation on Facebook: A lens model approach". Humor: International Journal of Humor Research 27/1: 1-21.

Plester, Beverly/Wood, Clare/Joshi, Puja (2009): "Exploring relationships between traditional and new media literacies: British preteen texters at school". Journal of Computer-Mediated Communication 14: 1108-1129.

Reeves, Bob (2007): Teach yourself: The internet and email for the over 50s. London: Hodder Education.

Shortis, Tim (2007): "Gr8 Txpectations. The Creativity of Text Spelling". English Drama Media 8: 21-26.

Tagg, Caroline (2012): The discourse of text messaging: Analysis of SMS communication. London: Continuum.

Tagg, Caroline (2015): Exploring digital communication: Language in action. London: Routledge.

Tannen, Deborah (2013): "The medium is the metamessage. Conversational style in new media interaction". In: Tannen, Deborah/Trester, Anna M. (eds.): Discourse 2.0: Language and new media. Washington DC, Georgetown University Press: 99-117.

Thimm, Caja (2008): "Technically-mediated interpersonal communication". In: Antos, Gerd/ Ventola, Eija (eds.): Handbook of interpersonal communication. Berlin/New York: Mouton de Gruyter: 331-353. 
Thurlow, Crispin (2013): "Fakebook. Synthetic media, pseudo-sociality and the rhetorics of Web 2.0". In: Tannen, Deborah/Trester, Anna M. (eds.): Discourse 2.0: Language and new media. Washington DC, Georgetown University Press: 225-249.

Thurlow, Crispin (2012): "Determined creativity: Language play in new media discourse". In Jones, Rodney H. (ed.): Discourse and creativity. Harlow, Pearson Education: 169-190.

Thurlow, Crispin/Brown, Alex (2003): "Generation Txt? The sociolinguistics of young people's text messaging". Discourse Analysis Online. http://extra.shu.ac.uk/daol/articles/v1/ n1/a3/thurlow2002003.html [08.07.2010].

West, Laura/Trester, Anna M. (2013): "Facework on Facebook. Conversations on social media". In: Tannen, Deborah/Trester Anna M. (eds.): Discourse 2.0. Language and new media. Washington DC, Georgetown University Press: 133-154.

Zimmer, Michael (2010): "But the data is already public: On the ethics of research in Facebook". Ethics and Information Technology 12/4: 313-325. 